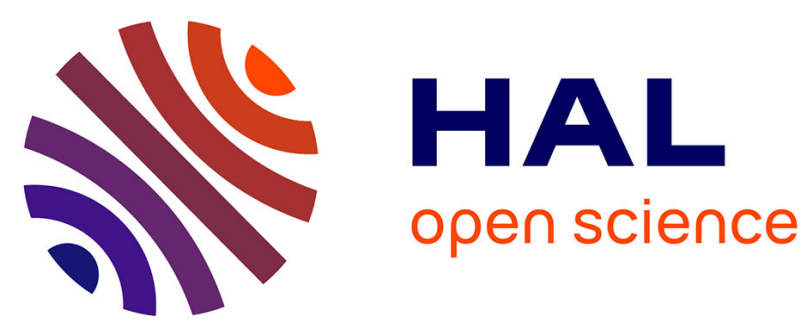

\title{
Water in Carbon Nanotubes: The Peculiar Hydrogen Bond Network Revealed by Infrared Spectroscopy
}

Simona Dalla Bernardina, Erwan Paineau, Jean-Blaise Brubach, Patrick Judeinstein, Stéphan Rouzière, Pascale Launois, Pascale Roy

\section{To cite this version:}

Simona Dalla Bernardina, Erwan Paineau, Jean-Blaise Brubach, Patrick Judeinstein, Stéphan Rouzière, et al.. Water in Carbon Nanotubes: The Peculiar Hydrogen Bond Network Revealed by Infrared Spectroscopy. Journal of the American Chemical Society, 2016, 138, pp.10437 - 10443. 10.1021/jacs.6b02635 . hal-03330294

\section{HAL Id: hal-03330294 \\ https://hal.science/hal-03330294}

Submitted on 1 Sep 2021

HAL is a multi-disciplinary open access archive for the deposit and dissemination of scientific research documents, whether they are published or not. The documents may come from teaching and research institutions in France or abroad, or from public or private research centers.
L'archive ouverte pluridisciplinaire HAL, est destinée au dépôt et à la diffusion de documents scientifiques de niveau recherche, publiés ou non, émanant des établissements d'enseignement et de recherche français ou étrangers, des laboratoires publics ou privés. 


\section{Water in carbon nanotubes: the peculiar hydrogen bond network revealed by infrared spectroscopy}

Simona Dalla Bernardina†, Erwan Paineauł, Jean-Blaise Brubach†, Patrick Judeinstein§, Stéphan Rouzière $\neq$, Pascale Launois* $¥$ and Pascale Roy*${ }^{*}$

† Synchrotron SOLEIL, AILES beamline, L’Orme des Merisiers, Saint Aubin, BP 48, 91192 Gif sur Yvette Cedex, France

‡ Laboratoire de Physique des Solides, CNRS, Univ. Paris-Sud, Université Paris Saclay, 91405 Orsay Cedex, France

§ Laboratoire Léon Brillouin, CNRS-CEA-UMR 12, CEA-Saclay, Université Paris-Saclay, 91191 Gif sur Yvette Cedex, France

KEYWORDS: Carbon nanotube, confinement, water, hydrogen bond, infrared spectroscopy

ABSTRACT: A groundbreaking discovery in nanofluidics was the observation of the tremendously enhanced water permeability of carbon nanotubes, those iconic objects of nanosciences. The origin of this phenomenon is still a subject of controversies. One of the proposed explanations involves dramatic modifications of the H-bond network of nano-confined water with respect to that of bulk water. Infrared spectroscopy is an ideal technique to follow modifications of this network through the inter- and intra-molecular bonds of water molecules. Here we report the first infrared study of water uptake at controlled vapor pressure in single walled carbon nanotubes with diameters ranging from 0.7 to $2.1 \mathrm{~nm}$. It reveals a predominant contribution of loose $\mathrm{H}$ bonds even for fully hydrated states, irrespective of the nanotube size. Our results show that, while the dominating loosely bond signature is attributed to a one-dimensional chain structure for small diameter nanotubes, this feature also result from a water layer with "free" $\mathrm{OH}$ (dangling) bonds facing the nanotube wall for larger diameter nanotubes. These experimental findings provide a solid reference for further modeling of water behavior in hydrophobic nanochannels. 


\section{INTRODUCTION}

Single walled carbon nanotubes (SWCNTs), as ultimate one-dimensional channels, represent an ideal model system for studying nanoconfinement. Water molecules, when confined inside nanochannels with diameters comparable to their size, do exhibit anomalous behavior, such as a variety of specific water ice phases ${ }^{1,2}$ or tremendously enhanced water flow, as highlighted a decade ago.3,4 Consequently, SWCNTs have been proposed as promising candidates for water filtration,5,6 singlemolecule sensors, ${ }^{7,8}$ ion selectivity, ${ }^{9}$ or energy applications. ${ }^{10}$ More generally, the unique behavior of water at the nanoscale is also of concern to biology, where the extreme water permeability of aquaporins, those membrane proteins developing nanopores, is crucial for many physiological processes, ${ }^{11}$ as well as with respect to the unimpeded permeation of water through graphenebased membranes. ${ }^{12,13}$

The water structure inside SWCNTs has been widely studied in recent years by numerical simulations. ${ }^{1-17}$ Although the results of these simulations strongly depend on the water model used, ${ }^{16-18}$ the broad picture that emerges from these calculations concerns structuring phenomena, from a single-file mode in nanotubes with the smallest diameters $(0.6-0.8 \mathrm{~nm})$ to a layered structure for larger nanotube diameters. ${ }^{15}$ These predictions have been confirmed experimentally by X-ray and neutron scattering, ${ }^{19-21}$ nuclear magnetic resonance, ${ }^{20,22,23}$ and resonant Raman scattering. ${ }^{24}$ It is worth noting here that the intermolecular structure of water upon confinement departs strongly from what is observed in bulk water implying strong modifications of the H-bond network. The fast water transport through SWCNTs has been explained by several authors as due to H-bond modifications in the hydrophobic nanochannels, ${ }^{14,25}$ while others focused on geometrical effects and curvature-induced incommensurability between water and carbon wall. ${ }^{26}$. The origin of the ultrafast water transport in CNTs thus remains still to debate. Experimental approaches have not yet provided a guidance to theory and numerical simulations ${ }^{14,25-27}$. Within this framework, an experimental analysis of the $\mathrm{H}$-bond network of water confined in SWCNTs thus appears mandatory. Infrared (IR) spectroscopy in a wide spectral range is a technique of choice to probe the hydrogen bond network. ${ }^{28}$ It has been successfully applied to study water confined in hydrophilic nanometer size structures such as zeolite, ${ }^{29}$ or silica glasses. ${ }^{30}$ In the case of sub-2-nanometer SWCNTs, the Hbond network of confined water molecules is predicted to be markedly weaker than that in bulk water ${ }^{31}$. Consequently, a high frequency vibration peak should be observed in the mid-IR spectrum of water confined in SWCNTs, attributed to loosely bound molecules, i.e. those which have only established two or less bonds with neighboring molecules. But up to now, the only IR absorption measurements reported in the literature of water in SWCNTs ${ }^{2,33}$ have failed to reveal any of the specific modifications to the vibrational spectrum predicted for water confined in carbon nanotubes. ${ }^{27}$

In this article, we report the first infrared study, at controlled vapor pressures, of the water dynamics in single walled carbon nanotubes with diameters ranging from 0.7 to $2.1 \mathrm{~nm}$. Our results reveal that water molecules confined in SWCNTs remain loosely bound even for fully filled tubes. The specific thermodynamic and transport properties of water in such nanotubes are benchmarked against these new experimental results.

\section{EXPERIMENTAL DETAILS}

Single Walled Carbon Nanotubes (>95 vol\% CNT; >90 vol\% SWCNT) were bought from Nanostructured \& Amorphous Materials, Inc. (NanoAmor). As specified by the manufacturer, the length of the tubes is between 1 and $3 \mu \mathrm{m}$. Raman spectroscopy experiments performed at different incident energies $(1.2,1.9$ and $2.2 \mathrm{eV})$ were used to quantify nanotubes diameters. Based on the measurements of radial breathing mode frequencies ${ }^{34}$ they were found to range from 0.7 to $2.1 \mathrm{~nm}$. Moreover, the ratio $\mathrm{R}_{\mathrm{G} / \mathrm{D}}$ between the areas of the $G$ and $D$ bands is rather high $\left(R_{G / D \sim 19}\right)$ indicating a small amount of defects 34 (see Figure SI1). In addition, $\mathrm{C}-\mathrm{O}-\mathrm{C}$ and $\mathrm{C}=\mathrm{O}$ stretching modes bands 35 at 1100 $\mathrm{cm}^{-1}$ and $1710 \mathrm{~cm}^{-1}$ were not detected by infrared spectroscopy, confirming the structural quality of the nanotubes studied. X-ray scattering (XRS) experiments were undertaken at $\mathrm{CuK} \alpha$ wavelength. The measured intensity decreases monotonously up to $1.6 \AA^{-1}$ (Figure SI2a). The XRS diagram of a powder of isolated nanotubes with a well-defined diameter would present wide oscillations, the minima of which being related to the diameter value (see Figure SI2b). The effect of a distribution in diameters, illustrated here for a SWCNT powder $(2 \mathrm{r}=14 \AA)$ with diameters ranging between 6.5 and 21.5 $\AA$ (FWHM = $\pm 7.5 \AA$ ) is also presented in Figure SI2b. In this case, the oscillations are completely vanished in agreement with the experimental XRS diagram obtained for our sample (Figure SI2a), which confirms the wide distribution of nanotubes diameters. Moreover, if nanotubes were organized in bundles, corresponding diffraction peaks should be observed, as shown in ref. 21 (see also Figure SI2c). The absence of such peaks strongly suggests that in our sample, SWCNTs do not form bundles, due to the wide distribution in diameters. In the frame of the present study, water filling of SWCNTs with a narrow diameter distribution around $1.4 \mathrm{~nm}$ and forming bundles ${ }^{21}$ have also been measured using IR, but surprisingly these experiments did not allow obtaining exploitable water signature. A possible explanation is that part of these nanotubes being metallic and assembled in large bundles, each bundle contains some metallic SWCNTs leading to complex shielding effects. In the present sample where 
nanotubes do not assemble in bundles, such shielding effects are avoided for the non-metallic nanotubes.

Infrared measurements were performed at the AILES beamline of synchrotron SOLEIL. The Bruker IFS125 FT-IR spectrometer was equipped with a $6 \mu \mathrm{m}$ Mylar beam splitter and a $1.6 \mathrm{~K}$ bolometer for terahertz measurements (THz range: $20-60 \mathrm{~cm}^{-1}$ at $2 \mathrm{~cm}^{-1}$ resolution), the same beam splitter and a $4.2 \mathrm{~K}$ bolometer for far infrared measurements (FIR range: $50-500 \mathrm{~cm}^{-1}$ at $2 \mathrm{~cm}^{-1}$ resolution), and a $\mathrm{KBr}$ beam splitter combined with a wide range $4.2 \mathrm{~K}$ bolometer for mid infrared (MIR range: $500-4000 \mathrm{~cm}^{-1}$ at 4 $\mathrm{cm}^{-1}$ resolution). The sample consists of a thin layer of nanotubes deposited on a gold grid placed at normal incidence relative to the incident beam. The sample holder was placed in a hydration cell especially designed for insitu infrared measurements under controlled vapor pressure. ${ }^{36}$

Prior to hydration, adsorbed species were removed by heating nanotubes in situ at $310 \mathrm{~K}$ for 12 hours under vacuum $\left(10^{-6} \mathrm{mbar}\right)$, using a cell inlet allowing for gas input/output or turbomolecular pumping ${ }^{36}$. Gas dosage and measurements were performed in regulated static conditions at $298( \pm 0.2) \mathrm{K}$. Different values of water vapor pressure $\mathrm{P}$ were set, corresponding to $9 \%, 30 \%, 55 \%$ and $100 \%$ relative humidity $\mathrm{R}_{\mathrm{H}}=\left(\mathrm{P} / \mathrm{P}_{\mathrm{o}}\right)^{*} 100, \mathrm{P}_{\mathrm{o}}$ being the water vapor pressure equal to $31.7 \mathrm{mbar}$ at $298 \mathrm{~K}$. The equilibrium was found to be reached (no more evolution of the IR spectra) in less than one hour for all water pressures and all measurements presented here were performed after several hours at the nominal water pressure.

Transmitted intensity modifications between the dry sample and the sample under a given water pressure are relatively weak (see Figure $1 \mathrm{~A}$ ), due to the small quantity of adsorbed water and the strong scattering by nanotubes powder. Data are thus presented in absorbance difference, subtracting the absorbance of the dry sample from the one of the sample exposed to a given water pressure, in order to highlight the modifications occurring when the system passes from the dry state to a hydrated one. Absorbance difference (Figure ${ }_{1} \mathrm{~B}$ ) is defined as $\mathrm{A}=-\log \left(I / I_{0}\right)$ where $I$ and $I_{o}$ are respectively the transmitted intensities with a given value of relative humidity $\left(\mathrm{R}_{\mathrm{H}}=100 \%\right.$ in Figure $\left.1 \mathrm{~A}\right)$ and in the dry state (black curve in Figure $1 \mathrm{~A}$ ). Positive absorbance is therefore related to water molecules sorption in the sample and to residual water vapor present in the cell during hydration. In order to remove the water vapor contributions, appearing as narrow structures on the spectra (red part in Figure $1 \mathrm{~B}$ ), additional experiments were performed in the same humidity conditions, with the sample holder (and the gold grid) but in the absence of CNTs, as shown in Figure $1 \mathrm{C}$. The expanded curve in figure ${ }_{1 C}$ evidences a broad structure centered at $3370 \mathrm{~cm}^{-1}$ characteristics of condensed water. This feature shows that a tiny quantity of water (less than $5 \%$ of the total amount of water adsorbed in CNTs at $\mathrm{R}_{\mathrm{H}}=100 \%$ ) is deposited on surfaces present in the light path (diamond cell windows or sample holding gold grid). The precise measurement of these water molecules contribution (vapor water as well as liquid water deposited on the sample holder or on the diamond windows) allows the spectra of hydrated CNT to be corrected and the specific spectral signature of water sorption in CNTs to be determined (Figure $1 D$ ).
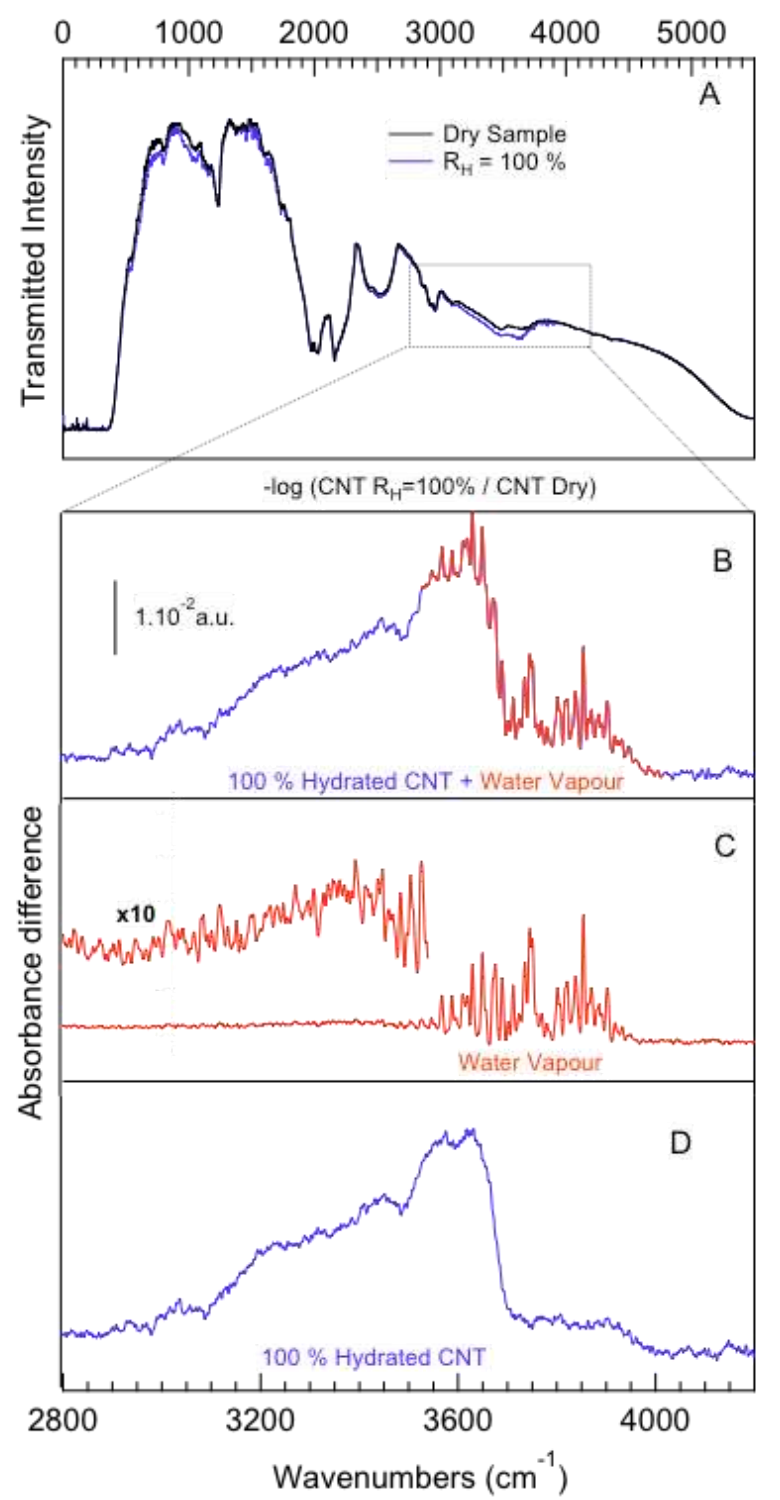

Figure 1. Data processing steps, on the example of SWCNTs under $\mathrm{H}_{2} \mathrm{O}$ vapor pressure, for $\mathrm{R}_{\mathrm{H}}=100 \%$. (A) Measurement of transmitted intensity through dry CNT $\left(\mathrm{I}_{0}\right)$ and hydrated CNT (B) Absorbance $-\log \left(\mathrm{I} / \mathrm{I}_{\mathrm{o}}\right)$ of water inside SWCNTs calculated from A. (C) Absorbance of water vapor inside the hydration cell under the $100 \%$ relative humidity in the empty cell under the same experimental conditions than (B), used as reference. The expanded curve presented above shows a minor contribution from water deposited on cells elements 
present in the light path. (D) Absorbance of water inside SWCNTs with vapor contribution (from C) removed. All absorbance differences are plotted in absorbance units (a.u.).

\section{RESULTS AND DISCUSSION}

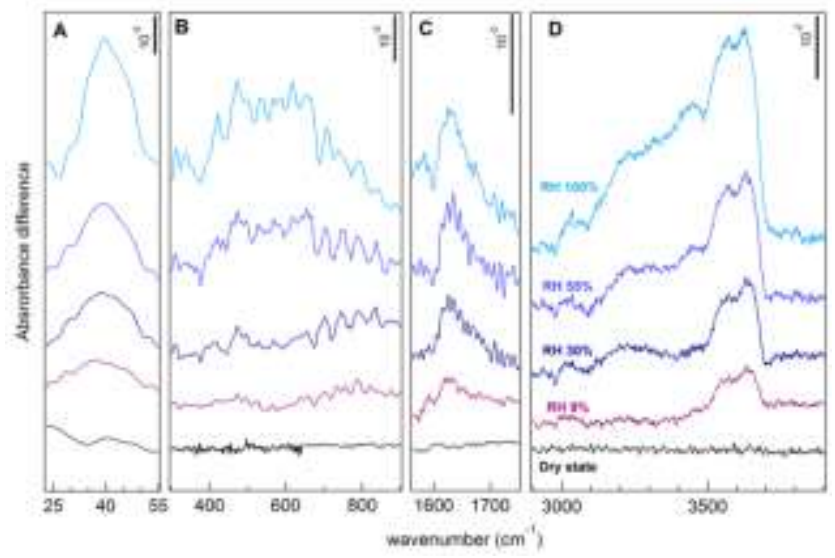

Figure 2. Absorbance of water inside SWCNTs from dry state to $9 \%, 30 \%, 55 \%$, and $100 \%$ of relative humidity. Water content increases from bottom to top. Different spectral ranges are shown to highlight vibrational modes of adsorbed water during hydration: (A) around $40 \mathrm{~cm}^{-1}$; (B) around 560 $\mathrm{cm}^{-1}(\mathrm{C})$ around $1625 \mathrm{~cm}^{-1}$; (D) between 3100 and $3700 \mathrm{~cm}^{-1}$. Spectra are translated vertically for the sake of clarity.

Difference spectra of the hydration sequence were performed in the THz $\left(20-50 \mathrm{~cm}^{-1}\right)$, FIR $\left(50-500 \mathrm{~cm}^{-1}\right)$ and MIR (500-4000 $\mathrm{cm}^{-1}$ ) regions; the observed absorption bands are displayed in Figure 2 from the dry state (bottom) to $\mathrm{R}_{\mathrm{H}}=100 \%$. One can observe the $\mathrm{OH}$ stretching band between 3100 and $3700 \mathrm{~cm}^{-1}$ (Figure $2 \mathrm{D}$ ), the water bending mode around $1625 \mathrm{~cm}^{-1}$ (Figure $2 \mathrm{C}$ ), its libration mode around $560 \mathrm{~cm}^{-1}$ (Figure $2 \mathrm{~B}$ ), as well as a low frequency mode at $40 \mathrm{~cm}^{-1}$ (Figure $2 \mathrm{~A}$ ). These experimental results can be compared with the calculated IR spectra in ref. 27, where Martí and Gordillo considered water confined inside SWCNTs with diameters ranging from 0.8 to $1.6 \mathrm{~nm}$ (see Table 1). The calculated spectra exhibit clear stretching, bending and libration modes, in agreement with our experimental spectra (Figure 2). In our experiments, we notice that the bending mode of water, at $1625 \mathrm{~cm}^{-1}$, is red shifted by $\sim 35 \mathrm{~cm}^{-1}$ compared to bulk water bending, typically observed at $1660 \mathrm{~cm}^{-1} .37$ Martí and Gordillo have also predicted a red shifted bending vibration at $1615 \pm 10$ $\mathrm{cm}^{-1}$ for water confined in SWCNTs. ${ }^{27}$ In a similar manner, the libration at $560 \mathrm{~cm}^{-1}$ appears red shifted compared to the bulk value $\left(680 \mathrm{~cm}^{-1}\right)$ in good agreement with predictions for water inside nanotubes. ${ }^{27}$

The assignment of the mode at $40 \mathrm{~cm}^{-1}$ is less straightforward, although its intensity gradually increases upon water sorption (see Figure 2), like those of the libration, bending and stretching modes, confirming that it should be attributed to water progressively encapsulated inside SWCNTs. It is worth noting that such a low energy feature had also been predicted by Martí and Gordillo ${ }^{27}$ who based their assignment on a comparison with a Raman study on bulk water by Walrafen ${ }^{38}$. This author attributes the low energy band to the bending of hydrogen bonded $\mathrm{O}-\mathrm{O}-\mathrm{O}$ unit. Alternative assignment for bulk water may imply translations frustrated by cage effects independently of the hydrogen bond 39 . One can also discuss this mode in connection with numerical simulations for water in CNT by Kumar and coworkers ${ }^{4}$. Within this framework, it should be attributed to a transverse translational motion of a one-dimensional chain of water in the smallest diameter nanotubes $(\mathrm{D} \sim \mathrm{o} .8 \mathrm{~nm})$, which would thus be observed here for the first time. Such translation could be made infrared active by the preferential orientation of molecules trapped within the tube allowing for an induced dipolar moment.

Let's now consider the stretching band, the shape of which is found to be noticeably different from that of bulk water (Figure 3). The $\mathrm{OH}$ stretching band of water provides detailed information about its networking. Indeed, the oscillator strengths and thus associated vibrational frequencies decrease when coordination number increases. ${ }^{30}$ Stretching bands of bulk liquid and ice are reported in Figure 3. Both are well fitted with three Gaussian functions. For liquid water (Figure $3 \mathrm{~B}$ down), the high energy Gaussian is assigned to loosely bound water molecules (two, one or zero H-bonds), the lowest energy is representative of highly connected water (four $\mathrm{H}$-bonds) and the intermediate energy component is representative of water with a coordination number close to three. ${ }^{37,41}$ For ice water Ih (Figure $3 \mathrm{~A}$ down), a shift towards low frequencies is observed as the result of the establishment of the rigid tetrahedral network.
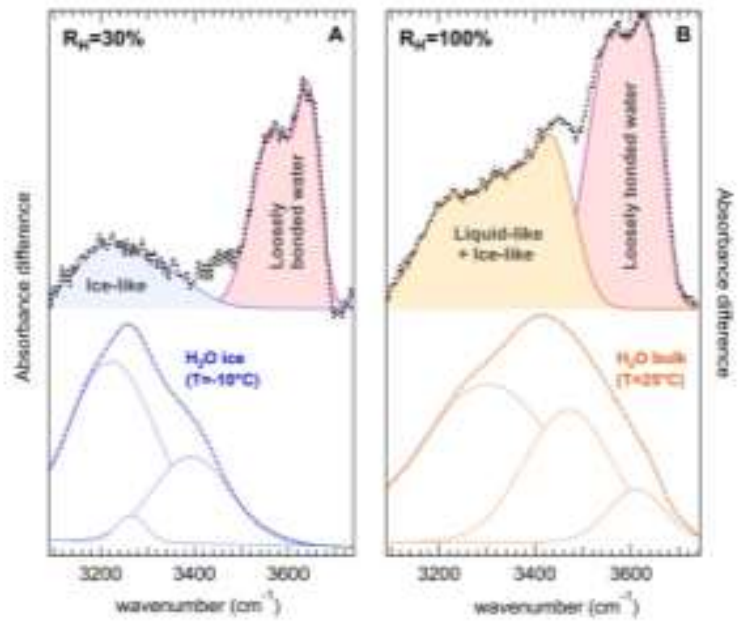

Figure 3. (A) $\mathrm{OH}$ stretching bands (3100-3740 $\left.\mathrm{cm}^{-1}\right)$ of water adsorbed in SWCNTs at $\mathrm{R}_{\mathrm{H}}=30 \%$ (top) and bulk ice water (bottoms. The ice-like contribution of confined water at low frequencies is highlighted in blue. (B) $\mathrm{O}-\mathrm{H}$ stretching bands of water adsorbed in SWCNTs at $\mathrm{R}_{\mathrm{H}}=100 \%$ (top) and 
bulk liquid water (bottom). The liquid-like+ice-like contribution of the adsorbed water at low frequencies is highlighted in orange. The contributions of loosely bound water molecules inside SWCNTs are highlighted in pink.

\begin{tabular}{|c|c|c|c|c|c|c|}
\hline \multicolumn{7}{|c|}{ Mode frequency $\left(\mathrm{cm}^{-1}\right)$} \\
\hline \multirow{3}{*}{\multicolumn{2}{|c|}{$\begin{array}{c}\text { Experimental results } \\
\text { Assignment }\end{array}$}} & \multicolumn{5}{|c|}{ Simulation results (from ref. 27) } \\
\hline & & \multirow{2}{*}{ Assignment } & \multicolumn{4}{|c|}{ tube diameter } \\
\hline & & & $8.2 \AA$ & $10.9 \AA$ & $13.6 \AA$ & $16.3 \AA$ \\
\hline Translation & 40 & Translation & -30 & $\sim 50$ & $\sim 50$ & $\sim 50$ \\
\hline Libration & 560 & Libration & 400 & 420 & 448 & 472 \\
\hline Bending & 1625 & Bending & $\sim 1625$ & $\sim 1615$ & $\sim 1615$ & $\sim 1605$ \\
\hline Stretching $\mathrm{G} 1$ & 3215 & & & & & \\
\hline Stretching $\mathrm{G}_{2}$ & 3340 & Symmetrical stretching & 3363 & 3420 & 3412 & 3411 \\
\hline Stretching $\mathrm{G}_{3}$ & 3435 & Asymmetrical stretching & 3707 & 3662 & 3657 & 3641 \\
\hline Stretching $\mathrm{G}_{4}$ & 3569 & & & & & \\
\hline Stretching $G_{5}$ & 3640 & & & & & \\
\hline
\end{tabular}

Table 1. Main component of confined water bands for $\mathrm{H}_{2} \mathrm{O}$ and comparison with simulation for various tube diameter from ref 27.

In the $3100-3500 \mathrm{~cm}^{-1}$ range, the absorbance of water confined in SWCNTs presents similarities either with bulk ice Ih, at $\mathrm{R}_{\mathrm{H}}=30 \%$, or with bulk water, at $\mathrm{R}_{\mathrm{H}}=100 \%$. Pascal and co-workers ${ }^{17}$ have discussed different stabilization mechanisms for water inside SWCNTs, depending on the nanotube diameter. In particular, an enthalpy stabilized, ice-like phase is predicted at room temperature for nanotube diameters of 1.1-1.2 $\mathrm{nm}$ while a liquid-like phase, stabilized by the increase of translational entropy, is predicted for nanotubes diameters above $1.4 \mathrm{~nm}$. It is also known that water adsorption isotherms in SWCNTs are of type $\mathrm{V}$, characterized by a low water uptake followed by a complete filling of the tubes until a threshold pressure is reached..$^{22}$ In addition, this threshold shifts to larger $R_{H}$ values when increasing the nanotube diameter. ${ }^{32,42}$ In consequence as smaller diameter nanotubes start trapping water first, the ice-like component visible at $\mathrm{R}_{\mathrm{H}}=30 \%$ in Figure $3 \mathrm{~A}$ can be attributed to a peculiar ice-like nanoconfined water formed in intermediate size nanotubes as corroborated by the recent X-ray diffraction results of Kyakuno et al. ${ }^{20}$ At higher water pressure, the filling of larger nanotubes dominates. ${ }^{32,43}$ Accordingly, the proportion of liquid-like confined water increases which is demonstrated by the appearance of a liquid-like contribution in the IR spectrum in Figure $3 \mathrm{~B}$.

A major difference between water confined in SWCNTs and bulk water is the presence of intense high frequency components between $3500-3700 \mathrm{~cm}^{-1}$. This important feature is a clear signature of loosely bound water molecules, due to the effect of confinement. ${ }^{27}$

This observation is truly original with respect to all experimental results on the dynamics of water inside SWCNTs published so far. 19,32,33,44 Indeed, Kolesnikov et al. 19 focused on large amplitude motions of $\mathrm{H}$ in SWCNTs while Byl et al.44 were concerned with nanoconfined ice at low temperature. The IR spectra in ref. 32 are unfortunately dominated by vapor pressure signatures while, surprisingly, room temperature IR study in ref. 33 does not show any specific confined water signature. It should also be underlined that, according to numerical simulations, a main difference between bulk water and water confined in SWCNTs is its reduced number of H-bonds $14,15,25,31,45-47$, leading to high frequency components for the confined water stretching band, ${ }^{27,48}$ in agreement with our measurements. In order to provide a complete picture, it is worth noting that water outside of carbon nanotubes can form a layered structure, as evidenced recently in photoluminescence experiments. ${ }^{49}$ Gordillo and Martí also considered water outside CNT in ref 50 and 51 . Based on their simulations, the $\mathrm{O}-\mathrm{H}$ high energy features dominating our spectra for every hydration level cannot be attributed to water around the nanotubes (indeed, only water confined between three SWCNTs within a bundle would present a high energy vibration, while in our sample, SWCNTs are not organized in bundles). Similarly, no major high frequency contribution is predicted for water at the surface of a graphene sheet ${ }^{45}$. We thus conclude that water outside the nanotubes cannot explain the observed peculiar shape of the stretching band.

A semi-quantitative analysis of the evolution of the stretching band with vapor water pressure is proposed, based on its deconvolution with five Gaussian functions $\mathrm{G} 1$, $\mathrm{G}_{2}, \mathrm{G}_{3}, \mathrm{G}_{4}$ and $\mathrm{G}_{5}$ centered at 3215, 3340, 3435, 3560 and $3640 \mathrm{~cm}^{-1}$, respectively (Figure 4 ). This number of independent component Gaussians was verified, by singular value decomposition ${ }^{52}$. Using this method, the total absorbance data at different relative humidity can be described with better than $99 \%$ accuracy by the first 5 basis functions (notice that the weakest of these 5 singular values contributes to $1.5 \%$ as compared to less than $0.01 \%$ for a sixth contribution, a value close to the spectra noise floor). This implies that a minimum of 5 independent Gaussians are required to describe the data. The fitting of the stretching region was realized using the LevenbergMarquardt algorithm to search for the minimum value of $\chi^{2}$. The relative areas of each subcomponent are used to quantify the evolution of the H-bond network during the filling of SWCNTs. In the first step of filling $\left(\mathrm{R}_{\mathrm{H}}=9 \%\right.$, Figure 
$4 \mathrm{~A})$, the stretching band is mainly composed of $(85 \%)$ the high frequency components $G_{4}$ and $G_{5}$. This feature can be attributed to loosely bound water with coordination number less or equal to two, forming one-dimensional (1D) chains in the narrowest nanotubes with diameter around $0.8 \mathrm{~nm},{ }^{14,27}$ or forming very local clusters. ${ }^{47}$ The presence of such high frequency $\mathrm{OH}$ sub component may indeed reflect two situations. If they are the only $\mathrm{OH}$ components, they strongly support the assembling in $\mathrm{1D}$ chains as these are the structure formed from one and two bound water molecules only. When they are present together with other sub-comments at lower frequency, they can also result from clusters with dangling $\mathrm{OH}$ bonds pointing toward the carbon walls.

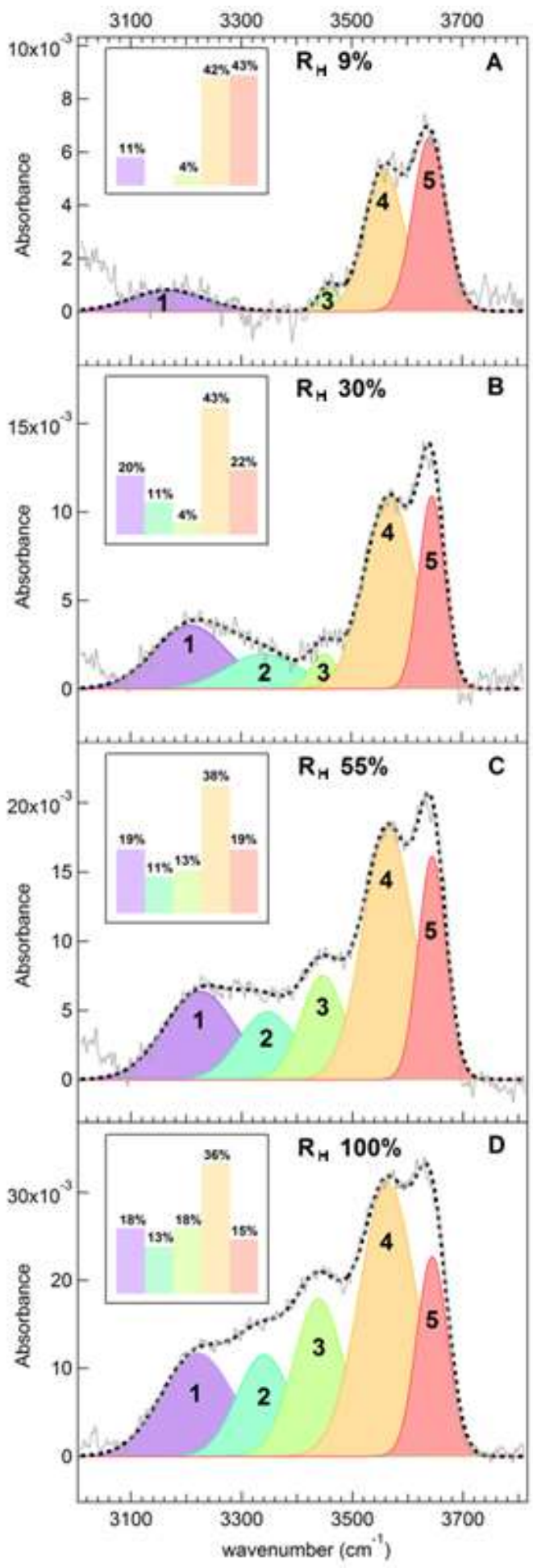

Figure 4. Deconvolution of the $\mathrm{O}-\mathrm{H}$ stretching band with five Gaussians for relative humidity of $9 \%$ (A), 30\% (B), $55 \%$ (C), and $100 \%$ (D). Inset: proportion (in percent) of each subcomponent. 
At $\mathrm{Rh}=9 \%$, a low energy contribution $\mathrm{G} 1$ is observed, which corresponds to ice-like $n$-gonal configurations and suggests the filling of nanotubes with diameters of 1.1-1.2 $\mathrm{nm} .{ }^{17,47}$ while the high frequency component $\left(\mathrm{G}_{4}+\mathrm{G}_{5}\right)$ is attributed to $1 \mathrm{D}$ chains in the smallest diameter nanotubes. This analysis is in agreement with the filling of water inside the smallest tubes at first, in accordance with adsorption isotherms for various tube diameters. ${ }^{32,42}$ As the water relative humidity increases $\left(\mathrm{R}_{\mathrm{H}}=30 \%\right)$, the amount of strongly bound water molecules increases, as demonstrated by the increase of the two low frequency components $\mathrm{G} 1$ and $\mathrm{G} 2$, Figure $3 \mathrm{~B}$. For $\mathrm{R}_{\mathrm{H}} \geq 50 \%$, in Figure ${ }_{4} \mathrm{C}, \mathrm{D}$, an intermediate component, $\mathrm{G}_{3}$, appears with a significant intensity at $3435 \mathrm{~cm}^{-1}$. The spectral distribution of $\mathrm{OH}$ stretching band between 3100 and $3500 \mathrm{~cm}^{-1}$ then resembles its bulk liquid counterpart (see Figure $3 \mathrm{~B}$ ) supporting an $\mathrm{H}$-bond network similar to bulk water. Accordingly, $\mathrm{G}_{3}$ appearance is concomitant with that of the libration band (Figure $2 \mathrm{~B}$ ). A progressive structuration of water in layers was previously observed by $\mathrm{X}$-ray scattering during $1.4 \mathrm{~nm}$ diameter nanotubes filling ${ }^{21}$ and such structuration is also expected to occur in nanotubes with diameters above $1.4 \mathrm{~nm} .{ }^{6-47} \mathrm{~A}$ non-negligible part of the high frequency signature $\left(G_{4}\right.$ and $\left.G_{5}\right)$ for $R_{H} \geq 50 \%$ should thus be attributed to the molecules in the layer closest to the carbon wall inside SWCNTs, with "free" OH bonds (dangling bonds) pointing towards the nanotube wall. Notice that simulations for water outside the carbon nanotube ${ }^{50,51}$ also predict a broad feature centered around $3350 \mathrm{~cm}^{-1}$. Consequently, on the basis of this comparison, one cannot exclude a contribution from water outside the tubes at hydration level above $50 \%$, however for hydration below $50 \%$, such contribution is negligible or absent.

We verified the trapping of water molecules using this time $\mathrm{D}_{2} \mathrm{O}$ vapor pressure. The same sample previously hydrated with $\mathrm{H}_{2} \mathrm{O}$ was pumped for several hours before hydration with $\mathrm{D}_{2} \mathrm{O}$. We present here the measurement on O-D stretching band where the largest isotopic effect is present. The inset allows a comparison with the bulk $\mathrm{D}_{2} \mathrm{O}$ absorbance. Compared to the bulk, the O-D stretching band for $\mathrm{D}_{2} \mathrm{O}$ in SWCNTs presents an intense highfrequency component (Figure 5) as it is also the case for confined $\mathrm{H}_{2} \mathrm{O}$. The SWCNTs absorbance difference extends from $2300-2750 \mathrm{~cm}^{-1}$ a range shifted by the ratio of the square root of reduced mass compared to the $\mathrm{O}-\mathrm{H}$ stretching ${ }^{37}$. Furthermore, the trapped water O-D is composed of five sub-components each precisely shifted (within 1\%) compared to the $\mathrm{OH}$ subcomponents and therefore confirming their similar assignment (cf Table 2). One may notice however, that in the $\mathrm{D}_{2} \mathrm{O}$ case, the high frequency subcomponents are not quite as dominant. It is worth noting that isotopic differences in band shape are also observed in the bulk stretching bands. Moreover, as shown in Figure $1 \mathrm{~A}$, this spectral domain corresponds to strong variations of the intensity transmitted by the diamond windows of the humidity cell, which limits our precision on the absolute intensity values.

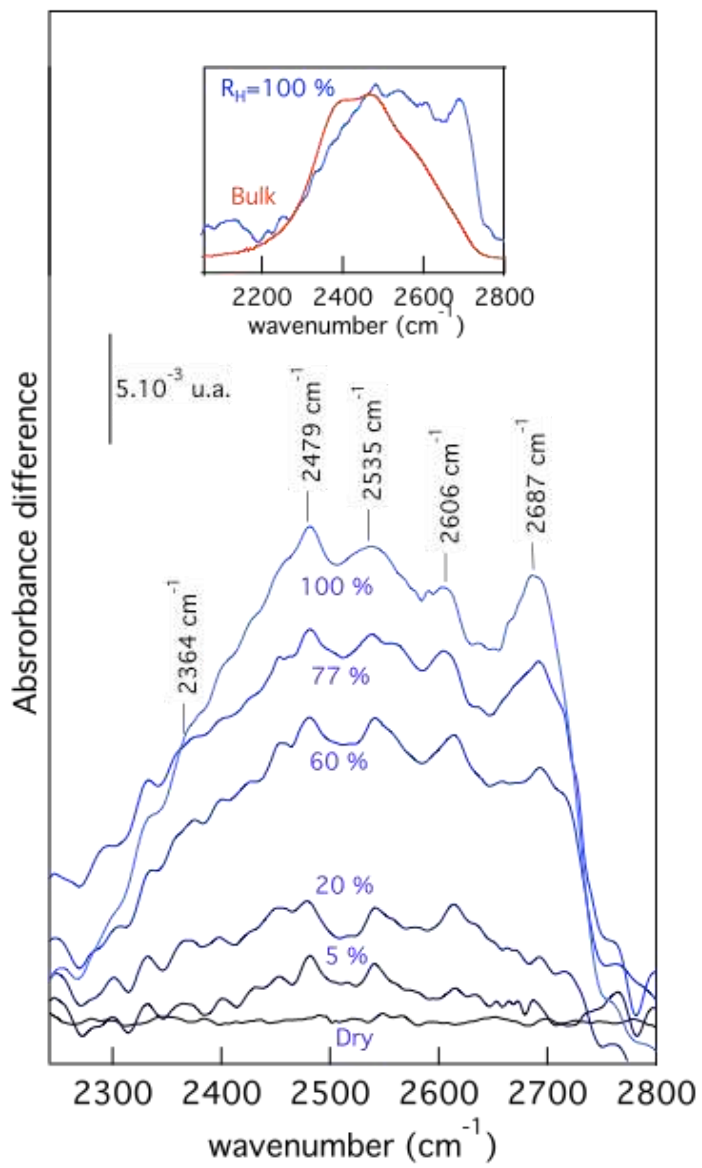

Figure 5. Absorbance of $\mathrm{D}_{2} \mathrm{O}$ inside SWCNTs from dry state to $5 \%, 20 \%, 60 \%, 77 \%$ and $100 \%$ of relative humidity. Water content increases from bottom to top. Inset comparison bulk $\mathrm{D}_{2} \mathrm{O}$ and $\mathrm{D}_{2} \mathrm{O}$ inside SWCNTs at $\mathrm{R}_{\mathrm{H}}=100 \%$.

\begin{tabular}{ccc|c}
$\begin{array}{c}\text { UO-H in CNT } \\
\text { Experimental } \\
\left(\mathbf{c m}^{-1}\right)\end{array}$ & $\begin{array}{c}\text { vO-D in CNT } \\
\text { Calculated } \\
\left(\mathbf{c m}^{-1}\right)\end{array}$ & $\begin{array}{c}\text { uO-D in CNT } \\
\text { Experimental } \\
\left(\mathbf{c m}^{-1}\right)\end{array}$ & $\begin{array}{c}\text { Difference } \\
\text { calculated / } \\
\text { experimental } \\
(\%)\end{array}$ \\
\hline 3215 & 2347 & 2364 & 0.7 \\
3340 & 2438 & 2479 & 1.7 \\
3435 & 2507 & 2535 & 1.1 \\
3569 & 2605 & 2606 & 0.02 \\
3640 & 2657 & 2687 & 1,1
\end{tabular}

Table 2. Main sub-component of confined water stretching bands for $\mathrm{H}_{2} \mathrm{O}$ and $\mathrm{D}_{2} \mathrm{O}$, and comparison of their frequencies. $1^{\text {st }}$ and $3^{\text {rd }}$ columns: measured values for $\mathrm{H}_{2} \mathrm{O}$ and $\mathrm{D}_{2} \mathrm{O} .2^{\text {nd }}$ column calculated value of $\mathrm{D}_{2} \mathrm{O}$ frequencies based on isotopic shift applied to $\mathrm{H}_{2} \mathrm{O}$ experimental values. $4^{\text {th }}$ column: relative difference between measured and calculated $\mathrm{D}_{2} \mathrm{O}$ frequencies.

In a context where our knowledge of the detailed water structure inside or outside SWCNTs is mainly based on 
numerical approaches, the present experimental data strongly suggest that $(i)$ the $1 \mathrm{D}$ structure of confined water in small diameter $(0.8 \mathrm{~nm})$ nanotubes, (ii) its ice-like structure in medium diameter (1.1-1.2 nm) nanotubes and (iii) the presence of a layer with "free" $\mathrm{OH}$ bonds facing the nanotube inner (or outer) wall for liquid water in larger diameter $(\geq 1.4 \mathrm{~nm})$ nanotubes. While our experimental data cannot be used to ascertain the presence of water layers outside nanotubes, their signal, if any, may reinforce that of the water layer facing the nanotube inner wall. Furthermore, our experimental results show that the water network is strongly affected by confinement and that more than half of the intensity of the stretching band comes from loosely bound water molecules, even for fully hydrated nanotubes.

The observation of ice-like water corroborates the theoretical approach developed to explain the spontaneous filling of hydrophobic carbon nanotubes, ${ }^{17}$ a counterintuitive phenomenon. Our results also support theoretical studies about the ultra-low friction of water through SWCNTs. Indeed, besides geometrical effects, ${ }^{26}$ it was claimed that the $1 \mathrm{D}$ structure of water inside the smaller diameter nanotubes or the peculiar hydrogen bonding at the interface in larger ones significantly eases the flow rates. ${ }^{14,25}$ The effect of one-dimensional confinement versus two-dimensional confinement could be elucidated by studying graphene-like membranes which were shown to be highly permeable to water, a property attributed to low friction flow of a monolayer of water between closely spaced graphene sheets. ${ }^{13}$ In this case, strong modifications of the $\mathrm{H}$ bonds networks and of the corresponding IR spectrum are also predicted ${ }^{28}$ and the experimental approach developed here should provide crucial information about water properties in graphenebased membranes. Finally, one should underline that simulations of nanoconfined water properties are mainly based on phenomenological models, each designed to explain specific bulk water properties, ${ }^{15}$ with modeldependent results. ${ }^{16,18}$ The present experimental data provide a solid reference for the elaboration of an energetic model accounting for the properties of water in hydrophobic nanochannels.

\section{AUTHOR INFORMATION}

\section{Corresponding Author}

*E-mail: (P.R.) pascale.roy@synchrotron-soleil.fr (P.L.) pascale.launois@u-psud.fr;

\section{Supporting Information Available}

Raman spectrum of the dried nanotubes measured at wavelength $=514 \mathrm{~nm}(2.41 \mathrm{eV})$. Details of X-Ray scattering (XRS) experiments on the dry SWCNT powder, XRS simulation formalism and additional figures This material is available free of charge via the Internet at http://pubs.acs.org.

\section{ACKNOWLEDGMENT}

We benefited from helpful discussions with Laurent Manceron, Stéphane Rols and Fransceco Capitani. We also acknowledge Rozenn Le Parc and Jean-Louis Bantignies for Raman analysis of the nanotubes diameters. Synchrotron SOLEIL is acknowledged for providing beamtime and for financial support during Simona Dalla Bernardina's Ph.D training. We thank John Bozec for a critical reading of the manuscript. EP, SR and PL benefited of a grant from the French Research National Agency under the program Investissements d'Avenir (ANR-10-LABX-oo35: Labex NanoSaclay).

\section{REFERENCES}

(1) Takaiwa, D.; Hatano, I.; Koga, K.; Tanaka, H. Proc. Natl. Acad. Sci. 2008, 105, 39-43.

(2) Mochizuki, K. Koga, K. Proc. Natl. Acad. Sci. 2015, 112, 82218226.

(3) Majumder, M.; Chopra, N.; Andrews, R.; Hinds, B. J. Nature 2005, 438, 44 .

(4) Holt, J. K.; Park, H. G.; Wang, Y.; Stadermann, M.; Artyukhin, A. B.; Grigoropoulos, C. P.; Noy, A.; Bakajin, O. Science 2006, 312, 1034-1037.

(5) Yang, H. Y.; Han, Z. J.; Yu, S. F.; Pey, K. L.; Ostrikov, K.; Karnik, R. Nature Comm. 2013, 4, 2220.

(6) Lee, B.; Baek, Y.; Lee, M.; Jeong, D. H.; Lee, H. H.; Yoon, J.; Kim, Y. H. Nature Comm. 2015, 6, 7109.

(7) Geng, J.; Kim, K.; Zhang, J.; Escalada, A.; Tunuguntla, R.; Comolli, L. R.; Allen, F. I.; Shnyrova, A. V.; Cho, K. R.; Munoz, D. et al. Nature 2014, 514, 612-615.

(8) Guo, S.; Meshot, E. R.; Kuykendall, T.; Cabrini, S.; Fornasiero, F. Adv. Mater. 2015, 27, 5726-5737.

(9) Thomas, M.; Corry, B.; Hilder, T. A. Small 2014, 10, 14531465.

(10) Park, H. G.; Jung, Y. Chem. Soc. Rev. 2014, 43, 565-576.

(11) Sui, H.; Han, B. G.; Lee, J. K.; Walian, P.; Jap, B. K. Nature $2001,414,872-878$.

(12) Cohen-Tanugi, D.; Grossman, J. C. Nano Lett. 2012, 12, 3602-3608.

(13) Nair, R. R.; Wu, H. A.; Jayaram, P. N.; Grigorieva, I. V. Science 2012, 335, 442-444.

(14) Hummer, G.; Rasaiah, J. C.; Noworyta, J. P. Nature 2001, 414, 188-19o.

(15) Alexiadis, A.; Kassinos, S. Chem. Rev. 2008, 108, 5014-5034.

(16) Nakamura, Y.; Ohno, T. Mater. Chem. Phys. 2012, 132, 682687.

(17) Pascal, T. A.; Goddard, W. A.; Jung, Y. Proc. Natl. Acad. Sci. 2011, 108, 11794-11798.

(18) Liu, L.; Patey, G. N. J. Chem. Phys. 2014, 141, 18C 518.

(19) Kolesnikov, A. I.; Zanotti, J. M.; Loong, C. K.; Thiyagarajan, P. Phys. Rev. Lett. 2004, 93, 035503.

(20) Kyakuno, H.; Matsuda, K.; Yahiro, H.; Inami, Y.; Fukuoka, T.; Miyata, Y.; Yanagi, K.; Maniwa, Y.; Kataura, H.; Saito, T.; Yumura, M.; Iijima, S. J. Chem. Phys. 2011, 134, 244501. 
(21) Paineau, E.; Albouy, P. A.; Rouzière, S.; Orecchini, A.; Rols S.; Launois, P. Nano Lett. 2013, 4, 1751-1756.

(22) Matsuda, K.; Hibi, T.; Kadowaki, H.; Kataura, H.; Maniwa, Y. Phys. Rev. B 2006, 74, 073415.

(23) Chen, Q.; Herberg, J. L.; Mogilevsky, G.; Wang, H. J.; Stadermann, M.; Holt, J. K.; Wu, Y. Nano Lett. 2008, 8, 1902-1905.

(24) Cambré, S.; Schoeters, B.; Luyckx, S.; Goovaerts, E.; Wenseleers, W. Phys. Rev. Lett. 2010, 104, 207401.

(25) Joseph, S.; Aluru, N. R. Nano Lett. 20o8, 8, 452-458.

(26) Falk, K.; Sedlmeier, F.; Joly, L.; Netz, R. R.; Bocquet, L. Nano Lett. 2010, 10, 4067.

(27) Martí, J.; Gordillo, M. C. Phys. Rev. B 2001, 63, 165430.

(28) Sharma, M.; Donadio, D.; Schwegler, E.; Galli, G. Nano Lett. 2008, 8, 2959-2962.

(29) Catafesta, J.; Alabarse, F.; Levelut, C.; Isambert, A.; Hébert, P.; Kohara, S.; Maurin, D.; Bantignies, J-L.; Cambon, O.; Creff, G.; Roy P.; Brubach, J-B.; Hammouda, T.; Andraultf, D.; Haines J. Phys.Chem.Chem.Phys., 2014, 16, 12202-12208.

(30) Le Caer, S.; Pin, S.; Esnouf, S.; Raffy, Q.; Renault, J. Ph.; Brubach, J.-B.; Creff, G.; Roy, P. Phys. Chem. Chem. Phys. 2011, 13, 17658-17666.

(31) Gordillo, M. C.; Martí J. Chem. Phys. Lett. 20oo, 329, 341345 .

(32) Ohba, T.; Kaneko, K.; Endo, M.; Hata, K.; Kanoh, H. Langmuir, 2013, 29, 1077-1082.

(33) Ellison, M. D.; Good, A. P.; Kinnaman, C. S.; Padgett, N. E. J. Phys. Chem. B 2005, 109, 10640-10646.

(34) Dresselhaus, M. S., Dresselhaus, G., Saito, R. \& Jorio, A. Physics Reports 2005, 409, 47-99.

(35) Kim, U. J., Liu, X. M., Furtado, C. A., Chen, G., Saito, R., Jiang, J., Dresselhaus, M. S. and Eklund, P. C. Phys. Rev. Lett. 2005, 95, 157402 .

(36) Dalla Bernardina, S.; Alabarse, F.; Kalinko, A.; Roy, P.; Vita, N.; Hienerwadel, R.; Berthomieu, C.; Judeinstein, P.; Zanotti, J. M.; Bantignies, J. L.; Haines, J.; Catafesta, J.; Creff, G.; Manceron, L.; Brubach, J. B. Vib. Spectrosc. 2014, 75, 154-161.

(37) Brubach, J. B.; Mermet, A.; Filabozzi, A.; Gerschel, A.; Roy,

P. J. Chem. Phys. 2005, 122, 184509.

(38) Walrafen G. E. J. Chem. Phys. 1964, 40, 3249-3256.

(39) Padró J.A.; Marti J. J. Chem. Phys. 2003, 118, 452.

(40) Kumar, H.; Mukherjee, B.; Lin, S. T.; Dasgupta, C.; Sood, A. K.; Maiti, P. K. J. Chem. Phys. 2011, 134, 124105

(41) Bergonzi, I.; Mercury, L.; Brubach, J. B.; Roy, P. Phys. Chem. Chem. Phys. 2014, 16, 24830-24840.

(42) Striolo, A.; Chialvo, A. A.; Gubbins, K. E.; Cummings, P. T. J. Chem. Phys. 2005, 122, 234712.

(43) Kim, P.; Zheng, Y.; Agnihotri, S. Ind. Eng. Chem. Res. 2008, 47, 3170-3178.

(44) Byl, O.; Liu, J. C.; Wang, Y.; Yim, W. L.; Johnson, J. K.; Yates, J. T. Jr. J. Am. Chem. Soc, 2006, 128, 12090-12097.

(45) Cicero, G.; Grossman, J. C.; Schwegler, E.; Gygi, F.; Galli, G. J. Am. Chem. Soc. 20o8, 130, 1871-1878.

(46) Hanasaki, I.; Nakatani, A. J. Chem. Phys. 20o6, 124, 174714 .

(47) Sadeghi, M.; Parsafar, G. A. Phys. Chem. Chem. Phys. 2013, 15, 7379-7388.

(48) Mann, D. J.; Halls, M. D. Phys. Rev. Lett. 2003, 90, 195503.

(49) Homma, Y.; Chiashi, S.; Yamamoto, T.; Kono, K.; Matsumoto, D.; Shitaba, J.; Sato, S. Phys. Rev. Lett. 2013, 110, 157402.

(50) Marti J., Gordillo M.C. J. Chem Phys., 2003, 119, 12540-
(51) Gordillo, M. C.; Martí J. Phys. Rev. B 2003, 67, 205425.

(52) Henry, E. R.; Hofrichter J. Methods in Enzymology 1992, 210, 129-192.

TOC

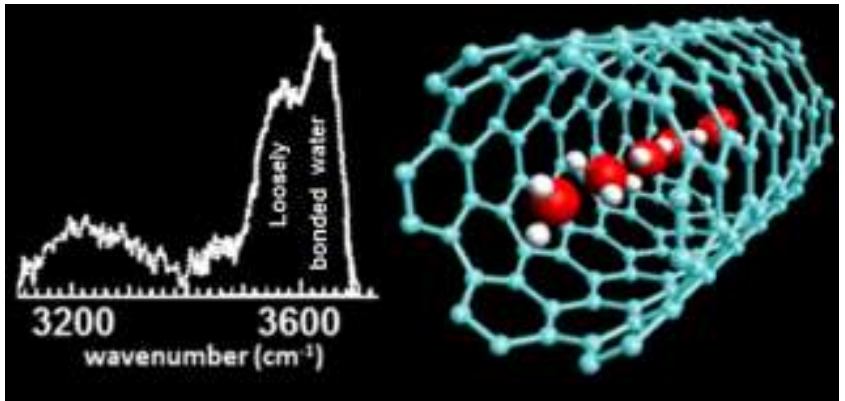
12546 . 